\title{
TURISMO DE MASSAS EM PORTUGAL: DA DESTRADICIONALIZAÇÃO À DESESTRUTURAÇÃO
}

\section{MASS TOURISM IN PORTUGAL: FROM THE DETRADITIONALIZATION TO THE DISRUPTION}

Eduardo C. Cordeiro Gonçalves Instituto Superior Da Maia - ISMAI. Portugal/Portugal egoncalves@,ismai.pt

Recibido/Received: 18/01/2012

Modificado/Modified: 24/09/2012

Aceptado/Accepted: 05/10/2012

\begin{abstract}
RESUMEN
Constituyendo una de las señas de identidad de la modernidad, el boom turístico de los años 1960-70 desafía a la sociedad portuguesa y se asocia de manera pronunciada al fenómeno de la destradicionalización, que marcó los últimos años del régimen del "Estado Novo" portugués. Partiendo, por lo tanto, del análisis de las características de la progresiva industrialización turista matizada por la reducción del tiempo y el aprisionamiento de los espacios turísticos, proponemos, por un lado, reflexionar sobre la racionalización y la mercantilización turística y, por otro, examinar las imágenes de masas que marcan el último cuarto del siglo XX portugués. Proponemos también poner en evidencia la inminente desintegración del modelo de turismo de masas en Portugal, donde imbrica la experiencia turística de la posmodernidad y la afirmación de un escenario global multidiferencial, que revela un campo de transacciones entre diferentes culturas y la hibridación como una constante.
\end{abstract}

\section{PALABRAS CLAVE}

Turismo de masas; mercantilización del turismo; postmodernidad; hibridación.

\section{SUMARIO}

1. Los orígenes del turismo de masas en Portugal. 2. Las políticas turísticas y de las autoridades públicas en Portugal: evolución del paradigma de desarrollo. 3. La "apropiación del espacio" y "compresión del tiempo". Bibliografía.

\begin{abstract}
Regarded as on of the marks of modernity the tourist boom from 1960 and 1970 represents a true challenge to the portuguese society associated to the phenomen of detraditionalization that marked the last years of "Estado Novo". Starting, therefore, from the analysis of the progressive industialization of tourism combined with the time compression and the imprisonement of the tourism areas, we propose to reflect, first about the rationalization and mercantilization and, secondly, about the imaginary mimicry that marks the last quarter of the twentieth century in Portugal. We also propose to talk about the imminente disintegration of the masss tourism model in Portugal where overlaps the tourist experience of post-modernity with the statement of a global multidimensional scenery which reveals a transitional field of different cultures and the hybridization as a constant.
\end{abstract}

\section{KEYWORDS}

Mass tourism; Mercantilization tourist; Postmodernity; Hybridity 


\section{CONTENTS}

1. The origins of mass tourism in Portugal. 2. Tourism policies and public authorities in Portugal: evolution of the paradigm of Development. 3. The " appropriation of spaces" and "time compression". References

\section{CONTEÚDO}

1. Das origins do turismo de massas em Portugal. 2. Políticas de turismo e poderes públicos em Portugal: evolução do paradigma de Desenvolvimento. 3. A "apropriação dos espaços" e a "compressão do tempo". Bibliografia

\section{DAS ORIGENS DO TURISMO DE MASSAS EM PORTUGAL}

Ao longo dos anos de 1960-70 a sociedade portuguesa foi perpassada por profundas mudanças estruturais, aceleradas pelo êxodo rural, pela industrialização e pela abertura económica à Europa, registando-se um intenso dinamismo de crescimento económico, de resto, a exemplo do que sucedeu, então, noutros países da Europa Meridional (Lopes, 2004: 113).

A estratégia desenvolvimentista do Estado Novo português vinha já a ser progressivamente ensaiada desde o após-guerra, por altura em que o lobby ruralista que influenciara as políticas públicas nos anos de 1930-40, mormente as plasmadas na organização corporativa e na coordenação económica ligada ao mundo rural (Rosas, 2000: 53), vai ceder terreno a uma nova elite tecnocrática. Sem se afastar do quadro ideológico do regime, este novo grupo, o dos "engenheiros", como era conhecido, propunha, assim, um projecto industrialista para Portugal.

Mas os anos de 1960 vão ficar marcados também por uma série de "figurações instabilizadoras" (Santos, 2002: 249) que assinalam o início do processo de destradicionalização do país. A este propósito, saliente-se o eclodir da guerra colonial no continente africano e o avolumar da emigração proveniente de um mundo rural atrasado e subprodutivo que se precipita numa "fuga gigantesca" para a Europa em expansão (Rosas, 1992: 497). Os níveis de emigração então registados vão provocar uma rarefacção da oferta de trabalho na lavoura e nalguns sectores da indústria, situação que se reflecte nos custos de produção, nos preços de bens alimentares, na habitação e nos excruciantes níveis de inflação, mormente a partir de 1965. Porém, tanto a emigração como a migração para os meios urbanos acabam por contribuir, sobremaneira, para a adopção de novos padrões comportamentais e de consumo, a que se associam novos hábitos e, em última análise, uma larvar alteração de mentalidades. Por sua vez, a composição social e profissional da população activa inicia uma vertiginosa mudança, salientando-se o acentuado decrescimento do sector primário que passou de 43,6\% em 1960 para menos de $10 \%$ nos finais dos anos 80 , a que correspondeu a subida no sector terciário no mesmo período de $27,5 \%$ para $51,3 \%$, correspondendo a uma nítida terciarização da economia e da sociedade portuguesa na espessura temporal indicada (Barreto, 2000).

Confrontamo-nos, assim, com um nítido processo de destradicionalização para o qual contribui ainda o recuo acentuado do analfabetismo e a crescente facilitação do acesso aos meios de comunicação de massas, mesmo que "fortemente policiados", e, naturalmente, o designado boom turístico que interpela a sociedade portuguesa dos últimos anos do regime estadonovista. 
Em termos teóricos, como é sabido, a destradicionalização decorre do "reconhecimento de que nem tradição nem inovação existem sob forma absoluta" (Fortuna, 1997: 2). Há componentes anti-tradicionalistas na tradição, como também se registam segmentos nãomodernizantes a par da inovação. Trata-se, pois, de um processo social através do qual as sociedades se modernizam e subordinam "anteriores valores, significados e acções" a uma nova lógica interpretativa e de intervenção. A esta luz, o turismo em Portugal enceta mais uma fase do seu desenvolvimento a partir de meados do século $\mathrm{XX}$, porquanto passa a ser considerado agora uma área de actividade económica relevante. Para trás fica o período em que o turismo era encarado sob a forma de um constructo ideológico delineado por António Ferro e que se respaldava numa base programática que pretendia alcançar a "ordem", a "estabilidade" e a "durabilidade" através da preservação do mundo rural (Gonçalves, 2009: 5).

O novo ciclo do turismo português, confirmado anos 60 adentro, regista um crescimento exponencial de turistas, sendo 1964 o ano da "explosão" da actividade turística, facto que irá atenuar o saldo até aí cronicamente deficitário da balança comercial, logo a seguir ao contributo histórico proporcionado pelas remessas dos imigrantes. Passa também a constituir fonte de proventos para inúmeras famílias para quem a lavoura já não era suficiente, isto em regiões da orla marítima.

Cada vez de modo mais marcante, a feição regionalista e folclórica vai sendo subvalorizada pelas opções industrialistas. Simultaneamente a este novo paradigma económico vai associar-se a expansão do tempo livre com novas rotinas de lazer e a progressiva sedimentação de modelos de consumo maciço e valores culturais contestatários, cuja dinâmica concorre com a decadente visão agrária.

Ainda ao longo da década de 60 do século passado enceta-se um ciclo de franca abertura ao investimento estrangeiro face á inevitabilidade industrialista, articulada com a adesão de Portugal à EFTA (Associação Europeia do Comércio Livre) que se revela uma importante componente de alavancagem propiciadora da vinda para o país de profissionais e quadros dirigentes provenientes da Europa desenvolvida. Por seu lado, o turismo acaba por ser complementar da emigração e do desenvolvimento do comércio externo em virtude da adesão de Portugal àquela organização internacional.

Este franco robustecimento da economia portuguesa pode ser averiguado nos programáticos Planos de Fomento, mormente no II Plano de Fomento e no Plano Intercalar (1965-1967). Aliás, tais instrumentos orientadores da economia passam a agrupar actividades que até então eram muito heterogéneas. O sector da restauração e hotelaria, bem como o dos transportes, irão, por assim dizer, beneficiar do forte dinamismo económico que se alongará até aos inícios da década de 1970. A este propósito, Silva Lopes, prestigiado economista português, sublinha que "Portugal participou em escala ampla no acolhimento das correntes turísticas dos países industrializados que atingiram números significativos durante esse período. As entradas de estrangeiros no território nacional aumentaram de 363.000 em 1960 para cerca de 4 milhões em 1973 (Lopes, 2004: 104). Lisboa e a ilha da Madeira são, então, os destinos que registam maior crescimento de fluxos turísticos. Do mesmo modo, há avanços no desenvolvimento da região do Algarve, uma região beneficiada por condições climatéricas propícias ao crescimento do segmento "Sol e Praia" que buscava o exemplo de sucesso de alguns destinos turísticos da vizinha Espanha, tal o caso de Alicante e Málaga. Tornam-se cada vez mais evidentes os sinais do estiolar de um atávico dilema do regime de "saber se seria necessário ter turistas para investir em infra-estruturas afins, ou se investir para atrair turistas” (Santos, 2002: 252). 
Fig.1 - Evolução da entrada de turistas em Portugal (em milhões)

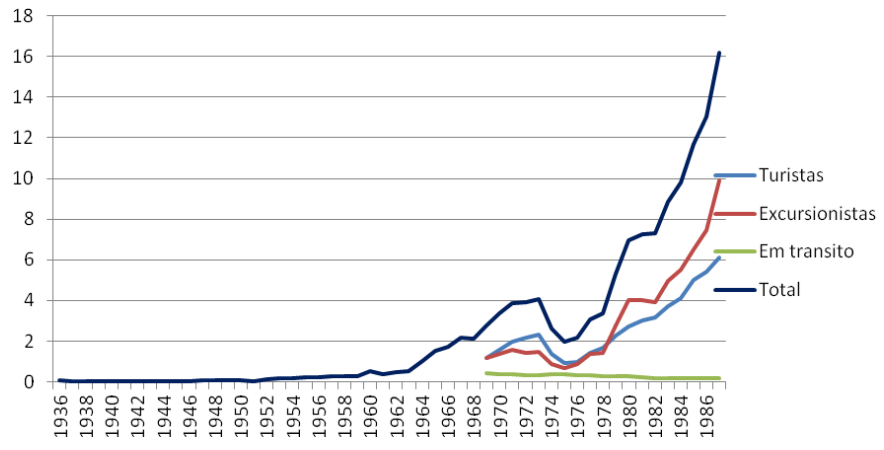

Fonte: Instituto Nacional de Estatística (Portugal); Elaboração Vitor Sá (CEDTUR/ ISMAI, 2012)

Mesmo assim, já nos alvores da década de 70, o chefe do Governo, Marcelo Caetano, desabafava que "com o turismo, era um pouco da alma do povo que se vendia" (Pina, 1988: 161). Retomando, porém, a linha institucionalizadora da $1^{\text {a }}$ República (Gonçalves, 2011), o poder político aprofunda o desenho orgânico do turismo com a criação da Direcção Geral de Turismo, em 1968, estrutura que passa a deter a tutela da formação turística articulada com a acção do então designado Instituto Nacional de Formação Turística (Brito, 2011).

Com o desvanecer dos motivos que fundamentaram as reservas em relação ao turismo, a par das quebras do isolamento, o país vai, de modo acelerado, consubstanciar a sua "turistificação" como processo compensatório do ónus económico advindo da Guerra Colonial (Cavaco, 1980). Em termos sociais, quer a busca de melhores condições de vida no litoral, quer o turismo e o desenvolvimento da construção civil irão pautar as expectativas de uma população serrana que se ajustará ao novo ritmo de vida, mais urbanizado, contrastando com o mundo rural de onde provinha.

\section{POLÍticas de TURISMO E PODERES PÚblicos EM PORTUGal: EVOLUÇÃO DO PARADIGMA DE DESENVOLVIMENTO}

Pese embora os Planos de Fomento evidenciarem, como ficou dito, as grandes orientações da economia portuguesa dos anos 60 e início de 70, onde se comtempla já uma política específica para o turismo (Vieira, 1997: 114), foi no Portugal democrático que os poderes públicos passaram a intervir no sector do turismo de modo concertado, isto sem se olvidar o esforço da iniciativa privada. Aliás, é no âmbito do FEDER (Fundo Europeu de Desenvolvimento Regional), em 1987, que se implementa um Sistema de Incentivos Financeiros ao Investimento no Turismo - SIFIT. Almejando-se a correcção dos desequilíbrios regionais a nível do desenvolvimento turístico, os fundos comunitários destinados ao seu incremento vão incidir, no essencial, no sector do alojamento, em novos produtos turísticos, bem como na formação profissional e na área dos transportes e comunicações (Costa, 2011). Mesmo assim, esta acção revela-se insuficiente para colmatar alguns dos principais problemas da indústria do turismo. 
Ao longo dos anos de 1990 passa a ser sublinhada a urgência em se implementar um novo modelo de desenvolvimento do turismo em Portugal, tal como o aponta a avaliação do II QCA (II Quadro Comunitário de Apoio) ao salientar algumas perplexidades relativas à dependência do produto "Sol e Praia", bem como à excessiva concentração da oferta nos destinos Lisboa, Madeira e Algarve, tudo isto a par do problema da sazonalidade e do afunilamento dos mercados e da escassez de mão de obra qualificada. Em contraponto, são aprofundados 4 novos segmentos de desenvolvimento estratégico, a saber: i) "Aumento da qualidade da oferta"; ii)"Incremento do profissionalismo"; iii) "Diversificação de produtos"; iv) "Diversificação de mercados".

Esta estratégia de incentivo ao turismo passa a contar com o redobrado apoio do FEDER e do FSE (Fundo Social Europeu), bem como de uma gama de medidas resultantes das acções Comunitárias, de que são bons exemplos os programas INTERREG II e LEADER II.

No sector privado o associativismo empresarial veio dar um novo fôlego ao turismo, mormente com criação da CTP (Confederação do Turismo Português), em 1995, que muito bem se articula com as novas políticas para o turismo português discutidas no âmbito das Grandes Opções do Plano desse mesmo ano. Aí se passa a referenciar o Estado como "coordenador" que deve apoiar o investimento empresarial do sector. No ano seguinte, a Direcção-Geral do Turismo divulga o Inventário de Recursos Turísticos do país, contribuindo, sobremaneira, para uma tomada de consciência sobre potencial da oferta turística portuguesa, mormente no que radica na herança e património cultural, no endógeno e no único.

\section{A "APROPRIAÇÃO DOS ESPAÇOS” E A "COMPRESSÃO DO TEMPO"}

Ora, desde os primórdios do turismo de massas, já na década de 1950, as expectativas geradas centravam-se no seu potencial como elemento de afirmação do intercâmbio cultural entre visitantes e visitados, ou seja, o conhecimento do outro e a consciência da alteridade. Esta capacidade do turismo foi, então, largamente divulgada pela Organização Mundial do Turismo, reportada de modo bem vincado nas afirmações de um dos primeiros teóricos da economia do turismo, W. Hunziker, que entendia que este se tornara "o primeiro instrumento de compreensão entre os povos [...] e um dos principais factores [da sua aproximação, bem como da] consequentemente manutenção de relações pacíficas" (Krippendorf,2001: 82). Por outro lado, a massificação do turismo acompanha, já nessa altura, a evolução tecnológica e o desenvolvimento dos transportes, a que acresce uma "indústria sem chaminés", o "marketing turístico" e a proliferação de um sem número de operadores turísticos (Santos, 2002: 258), tudo isto plasmado num quadro social marcado pela imagem e pela célere circulação da informação, com a afirmação do ócio e do tempo de recreio e lazer. Pressente-se, pois, o domínio da industrialização turística a apropriar-se dos espaços e a "comprimir o tempo", características de um período matizado pela reorganização fordista do trabalho, o que Cohen apelida de "experiência agenciada" onde se articula a atracção turística com os sítios e lugares criados com "propósitos turísticos", ou seja, opostos aos "locais físicos, culturais, étnicos ou arqueológicos que não tenham sido criados com propósitos turísticos” (Cohen, 1995: 15). O espaço abre-se, desta forma, á produção em massa. 
Assim se afirma um novo modelo de viagem em que o itinerário perde centralidade e passa a ligar-se intimamente ao "avião" que compreende também uma carga simbólica de "transcendência" (Durand, 1989:92). "Rotinizados e convencionais, os destinos passam a constituir os universos que habitam as viagens" (Santos, 2002:258), rapidamente secundarizadas e usadas tão-só como um meio para atingir um fim: o próprio destino. $\mathrm{O}$ turismo começa agora onde termina a viagem, acompanhando o declínio de um ethos apolínio que dá lugar a uma "cultura encorajadora do prazer" (BELL, 1976). O turismo de massas reivindica ainda a própria cultura como "esfera transaccionável". Os agentes turísticos buscam incessantemente as "idioculturas", ou seja, a produção de identidades locais que acabam por estar á mercê do dito "consumo transaccional". Passado, história, memória, comportamentos e rotinas transformam-se em acervos turísticos.

Com a experiência da globalização desenvolvesse uma "cultura global tectónica", veiculada pela ideia de que os sistemas de comunicação ao produzirem a "compressão de tempo-espaço", ao intensificarem a velocidade e intensidade dos fluxos turísticos, deixam pressentir que o mundo é um "lugar singular" no qual os indivíduos acabam por se fundir num espaço-entre, ou seja, na cultura da "aldeia global". Consigna-se, assim, uma globalidade de ideias, de padrões e valores culturais, de imaginários híbridos, em suma, de espaços e identidades intersticiais. Aqui imbrica a eminente desestruturação do modelo turístico de massas em Portugal, onde se cruza a experiência turística da pós-modernidade com a afirmação do "multidiferencial global" como lastro do movimento cultural de hibridização. Bom exemplo desta tendência é o redobrar da atenção prestada aos espaços de lusofonia. De resto, o desenvolvimento da nova experiência híbrida está também intimamente relacionado com a progressiva regressão do essencialismo identitário e a actualidade do multiculturalismo e da "política do reconhecimento". Desta experiência da globalização, quer pela afirmação das tecnologias do virtual e pela "virtualização técnica do imaginário híbrido" (Santos, 2002), emergem alguns dos mais significativos sinais da crise do modelo do turismo de massas que, num contexto mais englobante, é também sinal da designada crise da modernidade.

\section{BIBLIOGRAFIA}

BARRETO, A. (2000), A situação social em Portugal, 1960-1999. Lisboa: Imprensa de Ciências Sociais.

BARRETO, M. (2004), "Relações entre visitantes e visitados: em retrospecto dos estudos sócio antropológicos", en Turismo em Análise, n 2, pp. 133-149.

BELL, D. (1976), The cultural contradictions of capitalism. London: Heinemann.

BRITO, S. P. (2011), Direcção Geral do Turismo. Lisboa: Turismo de Portugal.

CAVACO, C. (1980), "O Turismo em Portugal: Aspectos evolutivos e espaciais", en Separata Estudos Italianos em Portugal, Lisboa, pp. 191-234.

COHEN, E. (1995), "Contemporary u tourism -trends and challaenges, sustainable authenticity or contrved pos-modernity?" en Butler, R. et al. (eds.), Change in tourism. London: Routdlegde.

DURAND, G. (1989), As estruturas antropológicas do imaginário. Lisboa: Presença.

FEATHERSTONE, M. (1991), Consumer culture and Post-Modernity. Londres: Sage.

FORTUNA, C. (1997), "Um caso de destradicionalização da imagem da cidade", Oficina do CES, no 91, Coimbra: Centro de Estudos Sociais.

GONÇALVES, E. C. (2009), Turismo em Espaço Rural: de António Ferro à Institucionalização. Maia: Edições ISMAI e CEDTUR. 
GONÇALVES, E. C. (2011), "Nas origens da institucionalização do Turismo em Portugal", en Gonçalves, E., et al. (dir.), Turismo e sociabilidades. Maia: Edições ISMAI e CEDTUR.

HOBSBAWM, E. y RANGER, T. (eds.), (1983), The invention of tradition. Oxford: Blackwell.

LOPES, J. S. (2004), A economia portuguesa no século XX. Lisboa: ICS.

MACHADO, F. L. (1977), "Contornos e especificidades da imigração em Portugal”, Sociologia, Problemas e Práticas, n 24 , pp.23-34.

McCANNELL, D. (1989), The tourist: A new theory of the leisure class. New York: Schocken Books.

MONS, A. (1992), La métaphore sociale. Paris: PUF.

PINA, P. (1988), O Turismo em no século XX. Lisboa: Lucidus Publicações.

ROSAS, F. (2000), Salazarismo e fomento económico: o primado do político na história económica do Estado Novo. Lisboa: Editorial Notícias.

ROSAS, F. (1998), O Estado Novo nos anos trinta. Lisboa: Editorial Estampa.

ROSAS, F. (1992), "O Estado Novo", en Matoso, J. (dir), História de Portugal. Lisboa: Circulo de Leitores, vol. 6.

SANTOS, F. (2002), Turismo - Mosaico de Sonhos: Incursões sociológicas pela cultura turística. Lisboa: Edições Colibri.

URRY, J. (1995): Consuming places. Londres: Routledge.

\section{Breve currículo:}

\section{Eduardo C. Cordeiro Gonçalves}

Doutorado pela Universidade do Porto (Portugal); Professor do Instituto Superior da Maia -ISMAI (Portugal); Director da Licenciatura em Turismo e do Mestrado em Turismo, Património e Desenvolvimento/ISMAI; Director do CEDTUR -Centro de Estudos de Desenvolvimento Turístico/ISMAI; Investigador principal do CETRAD- Centro de Estudos Transdisciplinar para o Desenvolvimento/I\&D 4011 da Fundação para a Ciência e a Tecnologia (Portugal); Editor Temático da PASOS: Turismo y Património Cultural (ULL, España). 